\title{
New Oral Anticoagulants: An Overview
}

\author{
Sunita Aggarwal', Pooja Anand' ${ }^{2}$, Rashmi Mishra $^{3}$, Naresh Kumar $^{4}$ \\ ${ }^{1}$ Professor of Medicine, ${ }^{2,3}$ Post Graduate Student, ${ }^{4}$ Associate Professor of Medicine, Department of Medicine, \\ Maulana Azad Medical College, New Delhi. \\ DOI: https://doi.org/10.24321/2349.7181.201804
}

\section{Introduction}

Oral anticoagulant therapy is used in the prevention and treatment of venous thromboembolism (VTE), prevention of stroke and other systemic emboli in patients with atrial fibrillation (AF) and artificial heart valves.

Vitamin K antagonists, particularly warfarin has been main stay for this therapy. However, it has several drawbacks, including a narrow therapeutic window, delayed onset of action, need for regular laboratory monitoring, considerable inter-individual variability in pharmacokinetics and pharmacodynamics and numerous interactions with drugs, food and acute illnesses.

In order to overcome some of the limitations with vitamin $\mathrm{K}$ antagonists, there has been intense research in developing new drugs with a more selective effect on coagulation factors, no need for monitoring, more predictable pharmacokinetics, fixed and convenient dosing regimens, rapid onset of action and, importantly, high efficacy and low risk of major bleeding. This has led to evolution of newer class of oral anticoagulants commonly termed as NOAC.

\section{Two classes of NOACs are currently available}

Oral direct thrombin inhibitor: Dabigatran

Oral factor Xa inhibitor: Rivaroxaban, Apixaban, Edoxaban

\section{Indications of $\mathrm{NOACs}^{4}$}

- Prevention of stroke and systemic embolism in patients with non-valvular AF with one or more risk factors

- Prevention of VTE following hip and knee replacement and

- Treatment of new and secondary prevention of deep vein thrombosis (DVT) and pulmonary embolism (PE)

NOAC use has not been studied in the following conditions: cerebral venous sinus thrombosis, portal and splenic vein thrombosis and non-lower limb DVT. They are not suitable for use in patients with hemodynamically significant valvular heart disease.

\section{Contraindications for NOAC therapy are $^{4}$}

1. Prior Hypersensitivity

2. Renal impairment

- Dabigatran (Pradaxa $\left.{ }^{\circledR}\right): \mathrm{CrCl}<30 \mathrm{~mL} / \mathrm{min}$

- Apixaban (Eliquis ${ }^{\circledast}$ ): $\mathrm{CrCl}<25 \mathrm{~mL} / \mathrm{min}$

- Rivaroxaban (Xarelto ${ }^{\circledR}$ ): $\mathrm{CrCl}<30 \mathrm{~mL} / \mathrm{min}$

3. Clinically significant active bleeding

4. Significant inherited or acquired bleeding disorder

Corresponding Author: Dr. Sunita Aggarwal, Department of Medicine, Maulana Azad Medical College, New Delhi.

E-mail Id: drsunita.mamc@gmail.com

Orcid Id: https://orcid.org/0000-0001-7635-6212

How to cite this article: Aggarwal S, Anand P, Mishra R et al. New Oral Anticoagulants: An Overview. J Adv Res Med 2018; 5(1): 13-15. 
1. Hepatic disease with coagulopathy

2. Organ lesions at risk of bleeding including intracranial haemorrhage in previous 6 months

3. Mechanical heart valve

4. Pregnant or breast feeding mother

\section{Role of Noac for Stroke Prevention in Non Valvular Af ${ }^{1}$}

- Compared with warfarin, dabigatran was associated with reduced risk of ischemic stroke, intracranial haemorrhage and mortality, but with an increased risk of GI bleeding. (RELY, RELY ABLE TRIALS).

- After a median follow-up of 1.93 years, rivaroxaban was non inferior to warfarin for the prevention of stroke or systemic embolism; however, rivaroxaban failed to show superiority over warfarin in the intention-totreat analysis. There were no differences in the risk of major bleeding, although intracranial and fatal bleeding occurred less frequently in the rivaroxaban group. Gastrointestinal bleeding and transfusion requirements were greater with rivaroxaban. (ROCKET AF TRIAL).

- After a mean follow up of 1.8 years, apixaban was significantly better than warfarin, with fewer primary outcomes (overall strokes-both ischaemic and haemorrhagic - and systemic emboli), but with no significant differences in rates of ischaemic strokes. Patients treated with apixaban had significantly fewer intracranial bleeds, but GI bleedings were similar between both groups. All-cause mortality was found to be significantly lower in the apixaban group. (ARISTOLE TRIAL).

- Apixaban was also compared with aspirin alone in the AVERROES study, a double-blinded study of 5599 patients who were not suitable candidates for VKA treatment. After a mean follow-up of 1.1 years, the study was prematurely stopped due to a clear benefit in favour of apixaban. The primary outcome of stroke or systemic embolism was significantly lower in the apixaban.

- Edoxaban was non-inferior to warfarin with respect to the prevention of stroke or systemic embolism. It was associated with lower, dose-related rates of bleeding, including major bleeding, intracranial bleeding, and life-threatening bleeding. The incidence rate of haemorrhagic stroke and the rate of death from cardiovascular causes were significantly lower with edoxaban. (ENGAGE AF TIMI TRIAL).

- Comparative analysis of the four NOACs confirmed that NOACs significantly reduced the composite of stroke or systemic embolic events by $19 \%$ compared with warfarin, which very much depended on large reduction in haemorrhagic strokes. Data for all four NOACS showed that they were associated with a $14 \%$ non-significant reduction in major bleedings.

\section{Role of NOACs in treatment of acute VTE}

- Dabigatrin was non inferior to warfarin in acute VTE treatment ( $2.4 \%$ vs $2.1 \%$ ) with no differences in major bleeding.(RECOVER and REMEDY TRIAL). ${ }^{5}$

- Rivaroxaban was non-inferior to warfarin for DVT(2.1\% vs $3 \%$ ) with similar bleeding risk, and also non inferior to warfarin for PE with lower bleeding risk than warfarin. (EINSTEIN DVT, EINSTEIN PE, EINSTEIN EXTENSION). ${ }^{6}$

- Apixaban was non-inferior to warfarin(2.3\% vs $2.7 \%$ ) for acute DVT and PE with significantly less bleeding. (AMPLIFY). ${ }^{7}$

- Edoxaban was non-inferior to warfarin in DVT and superior to warfarin in PE with similar bleeding risks in both conditions.(HOKUSAI VTE) ${ }^{8}$

\section{Current Recommendations in Renal Impairment}

\section{Dabigatran}

- $\quad \mathrm{CrCl}<30 \mathrm{ml} / \mathrm{min}$ : contraindicated

- $\mathrm{CrCl} 30-49 \mathrm{ml} / \mathrm{min}$ or age $>75$ years or weight $<60$ $\mathrm{kg}$ or high risk of bleeding ( HASBLED >3): $110 \mathrm{mg}$ BD

- $\mathrm{CrCl}>50 \mathrm{ml} / \mathrm{min}$ and age $<75$ years :150 mg BD

\section{Rivaroxaban}

- $\quad \mathrm{CrCl}<30 \mathrm{ml} / \mathrm{min}$ : contraindicated

- $\mathrm{CrCl} 30-49 \mathrm{ml} / \mathrm{min}: 15 \mathrm{mg}$ OD

- $\mathrm{CrCl}>50 \mathrm{ml} / \mathrm{min}$ : $20 \mathrm{mg}$ OD

\section{Apixaban}

- $\mathrm{CrCl}<25 \mathrm{ml} / \mathrm{min}$ : contraindicated

- $\mathrm{CrCl}>25 \mathrm{ml} / \mathrm{min}$ and at least two of following, age $>80$ years, weight $<60 \mathrm{~kg}$ and creatinine $>1.5 \mathrm{mg} / \mathrm{dl}$ : $2.5 \mathrm{mg} \mathrm{BD}$

- $\mathrm{CrCl}>25 \mathrm{ml} / \mathrm{min}: 5 \mathrm{mg} \mathrm{BD}$

Above dosing recommendations also apply for treatment of VTE and prevention of recurrent VTE.

\section{Noac Modification in Hepatic Impairment ${ }^{2,3}$}

\section{Dabigatran}

contraindicated in Child Pugh $\mathrm{C}$ and severe liver failure (ALT,AST elevation more than 2 times upper limit).

\section{Apixaban \& Rivaroxaban}

contraindicated in Child Pugh B and C, liver disease with coagulopathy.

\section{Monitoring $^{2,3}$}

- $\quad$ KFT to be monitored annually.

- Specific assays include dilute thrombin clotting time ( 
hemoclot assay) for dabigatran and modified anti Xa assay for rivoraxaban and apixaban.

\section{Clinical Challenges with NOACs}

- No validated tests to measure anticoagulation effect.

- No antidote for most agents.

- Balancing cost against efficacy.

- Lack of head- to- head studies comparing new agents.

- $\quad$ Potential for unknown long term adverse events.

\section{Conclusion}

New oral anticoagulants have a favourable balance between efficacy and safety compared with VKAs. Advantages of NOACs include rapid onset, fast clearance, fewer interactions with medications and food, and no need for laboratory monitoring.Patients best treated with newer anticoagulants are patients with poor warfarin control, poor level of control because of unavoidabale drug interactions and new patients on anti-coagulation therapy for AF.Choice of anticoagulant treatment should be based on patients' parameters like age, renal function, and drug history. Further research is ongoing to monitor the anticoagulant effects of the new agents, as well as development of antidotes for effective reversal of anticoagulation effect,and comparison between new agents.

\section{Conflict of Interest: None}

\section{Refrences}

1. Hinojar R, Jiménez-Natcher JJ, Fernández-Golfín C, Zamorano JL. New oral anticoagulants: a practical guide for physicians. European Heart Journal-Cardiovascular Pharmacotherapy. 2015 Feb 25;1(2):134-45.

2. Heidbuchel $H$, Verhamme $P$, Alings $M$, Antz $M$, Diener HC, Hacke W, Oldgren J, Sinnaeve P, Camm
AJ, Kirchhof P, Advisors:. Updated European Heart Rhythm Association Practical Guide on the use of nonvitamin $\mathrm{K}$ antagonist anticoagulants in patients with non-valvular atrial fibrillation. EP Europace. 2015 Aug 31;17(10):1467-507.

3. Raval AN, Cigarroa JE, Chung MK, Diaz-Sandoval LJ, Diercks D, Piccini JP, Jung HS, Washam JB, Welch BG, Zazulia AR, Collins SP. Management of Patients on nonvitamin $\mathrm{K}$ antagonist oral anticoagulants in the acute care and Periprocedural setting: a scientific statement from the American Heart Association. Circulation. 2017 Mar 7;135(10):e604-33.

4. Clinical Excellence Commission, 2017, Non-vitamin K Antagonist Oral Anticoagulant (NOAC) Guidelines, Updated July 2017 Sydney: Clinical Excellence Commission.

5. Schulman S, Kearon C, Kakkar AK, Mismetti P, Schellong S, Eriksson H, Baanstra D, Schnee J, Goldhaber SZ. Dabigatran versus warfarin in the treatment of acute venous thromboembolism. New England Journal of Medicine. 2009 Dec 10;361(24):2342-52.

6. Einstein Investigators. Oral rivaroxaban for symptomatic venous thromboembolism. New England Journal of Medicine. 2010 Dec 23;363(26):2499-510.

7. Agnelli G, Buller HR, Cohen A, Curto M, Gallus AS, Johnson M, Masiukiewicz U, Pak R, Thompson J, Raskob GE, Weitz JI. Oral apixaban for the treatment of acute venous thromboembolism. New England Journal of Medicine. 2013 Aug 29;369(9):799-808.

8. Hokusai-VTE Investigators. Edoxaban versus warfarin for the treatment of symptomatic venous thromboembolism. New England Journal of Medicine. 2013 Oct 10;369(15):1406-15.

Date of Submission: 2018-03-05 Date of Acceptance: 2018-03-31 